\title{
Research on Ion-Solvent Interactions in the Inorganic Liquid Mixtures by Ultrasonic Technique
}

\author{
K. Rathina, M. Umadevi, C. Senthamil selvi, Ramalatha Marimuthu
}

\begin{abstract}
Ultrasonic speed, density and viscosity of binary liquid mixtures of aqueous ammonium per sulphate with other sulphate solutions at 303.15 K have been measured. From these experimental data, the adiabatic compressibility, intermolecular free length, internal pressure, acoustic impedance, relaxation time, molar volume, classical absorption coefficient and surface tension have been computed. The excess viscosity, excess compressibility, excess intermolecular free length, excess acoustic impedance and excess molar volume values are evaluated to find the nature and the extent of the interactions between the constituent molecules of the liquid mixture systems.

Keywords: Molecular interaction, ammonium persulphate, Ultrasonic velocity, Relaxation time, excess acoustic impedance
\end{abstract}

\section{INTRODUCTION}

The structural arrangements and the change in physico chemical behavior of liquid mixtures are mainly due the change in molecular orientations and change in physical quantities .Ultrasonic velocity measurements and other acoustical parameters of liquid mixtures are the powerful technique in the understanding of chemical nature and the molecular interactions. Some earlier researches have shown that the propagation of ultrasound in the solution is the significant probing technique for the study of intermolecular the liquid mixtures ${ }^{1-7}$. Acoustical and thermo dynamical study of liquid mixtures provide enough knowledge about the association of molecular packing, molecular motion and strength of intermolecular interactions ${ }^{8}$. Thermodynamic and acoustical properties such as adiabatic compressibility, intermolecular free length, internal pressure, acoustic impedance, relaxation time, molar volume, classical absorption and surface tension are calculated from measured ultrasonic velocity, density and viscosity for binary mixtures and they are very much helpful to interpret nature and type of intermolecular interactions between the component molecules ${ }^{9}$.

Ultrasonic study of molecular interactions in binary liquid mixtures is widely useful in industrial and biological process. Molecular interaction study found enormous application in pharmaceutical, garment and food industries.

Revised Manuscript Received on August 14, 2019.

K. Rathina, Assistant Professor II, Department of Physics, Kumaraguru College of Technology, Coimbatore-641049, Tamil Nadu, India.(E-mail: rathina1008@gmail.com)

M. Umadevi, Department of Physics, Sri Parasakthi College for women, Courtallam-627802, Tamil Nadu, India.

C. Senthamil selvi, Department of Physics, Chellammal Women's College, Chennai-600032.Tamil Nadu, India.

Ramalatha Marimuthu, Department of Electronics and Communication Engineering, Kumaraguru College of Technology, Coimbatore-641049, Tamil Nadu, India. interactions and the structure of the constituent molecules of

The non linearity in the ultrasonic velocity and other acoustical quantities may arise from the structural modification of the molecules, and nature of interaction between the solute and solvent molecules ${ }^{10-13}$.

The excess parameters play a vital role in the understanding of the existence of complex formation in the liquid mixtures. The negative values of excess parameters exhibit the presence of strong interactions ${ }^{14}$. The shape of the molecule and the nature of the interactions intensely influence complex formation occurrence inside the liquid mixtures ${ }^{15}$.

It is observed from variety of literature survey, no ultrasonic investigation has been reported for the Ammonium persulphate with other sulphate anions. S.Ravichandran and K.Ramanathan analyzed the intermolecular interactions based on the acoustical properties and excess values in binary liquid mixtures of Zinc sulphate and Zinc nitrate ${ }^{16}$.

Ammonium persulphate is taken for our present study because of its industrial importance. It is a strong oxidizing agent and radical initiator. It is used to etch copper on printed circuit boards as an alternative to ferric chloride solution. It is also used along with tetra methyl ethylenediamine to catalyze the polymerization of acryl amide in making a polyacrylamide gel. It has also been utilized to study protein - protein interactions via photo initiated cross linking chemistry.

The present paper focused on ultrasonic investigation in the aqueous solutions of binary mixtures of following five systems. The whole study has been made at the temperature of $303.15 \mathrm{~K}$.

SystemI:.Ammonium Persulphate+Copper Sulphate

System II. Ammonium Persulphate + Ferrous ammonium sulphate

SystemIII. Ammonium Persulphate +Zinc Sulphate

System IV:.Ammonium Persulphate + Manganese Sulphate

SystemV:.Ammonium Persulphate +Ammonium Sulphate

From the measured ultrasonic speed $(\mathrm{U})$, density $(\rho)$, and viscosity $(\eta)$, adiabatic compressibility $(\beta)$, intermolecular free length $\left(L_{f}\right)$, internal pressure $\left(\pi_{\mathrm{i}}\right)$, acoustic impedance $(\mathrm{Z})$, relaxation time $(\tau)$, molar volume $\left(\mathrm{V}_{\mathrm{m}}\right)$, classical absorption co efficient $\left(\alpha / \mathrm{f}^{2}\right)$ and surface tension $(\sigma)$ have been evaluated. The surface tension for the liquid mixtures has been calculated by applying Altenberg relation between

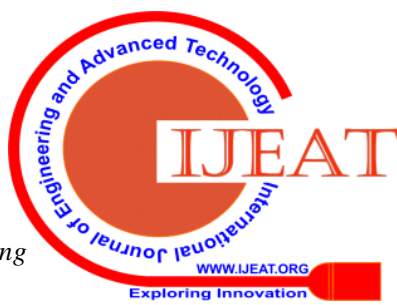




\section{RESEARCH ON ION-SOLVENT INTERACTIONS IN THE INORGANIC LIQUID MIXTURES BY ULTRASONIC TECHNIQUE}

ultrasonic velocity and density of liquid mixtures ${ }^{17}$. The excess viscosity $\left(\eta^{\mathrm{E}}\right)$, excess compressibility $\left(\beta^{\mathrm{E}}\right)$, excess intermolecular free length $\left(\mathrm{L}_{\mathrm{f}}^{\mathrm{E}}\right)$, excess acoustic impedance $\left(\mathrm{Z}^{\mathrm{E}}\right)$ and excess molar volume $\left(\mathrm{V}_{\mathrm{m}}^{\mathrm{E}}\right)$ values have been computed to study the nature of interaction among the liquid mixtures.

\section{EXPERIMENITAL}

The inorganic salts used for preparing liquid mixtures are AR grade from Merck. The solutions were prepared by using distilled water. Ultrasonic velocity for the liquid mixtures for all concentrations were measured with a single crystal ultrasonic interferometer with frequency of $2 \mathrm{MHz}$ (model F-81), manufactured from Mittal enterprises having accuracy in ultrasonic velocity of $\pm 0.02 \%$. The viscosity of The density of the solutions was measured by specific gravity bottle of $5 \mathrm{ml}$ with accuracy of $\pm 0.5 \%$.Ultrasonic speed, viscosity and density measurements had been made at $303.15 \mathrm{~K}$. The various acoustical parameters like adiabatic compressibility, intermolecular free length, internal pressure, acoustic impedance, relaxation time, molar volume, classical absorption coefficient and surface tension were calculated for the liquid mixtures. From the computed acoustical parameters, excess parameters were calculated.

\section{Theory and Calculations}

The acoustical parameters which are calculated from measured ultrasonic velocity density, and viscosity provide complete information about interaction between ions, dipoles, the intermolecular hydrogen bonding and cohesive and dispersive forces. The experimental values of ultrasonic velocity, density and viscosity of the binary liquid mixtures of all the five system are measured applying the standard procedure and formulae.

\section{Adiabatic compressibility}

The change in the adiabatic compressibility is due to the variation in the structural arrangement of molecules. It depends only on the ultrasonic velocity and density of the solution not the temperature.

Adiabatic compressibility can be calculated using the relation $^{18}$,

$$
\beta=\frac{1}{U^{2} \rho}
$$

\section{Intermolecular free length}

Free length is extremely important parameter to examine the nature and strength of interactions ${ }^{5}$. The free length is the distance between the surfaces of neighboring molecules. From Jacobson's Formula , free length is calculated as ${ }^{19}$

$$
L_{f}=K_{T} \beta^{\frac{1}{2}}
$$

where, $\mathrm{K}_{\mathrm{T}}$ is temperature dependent constant known as Jacobson constant.

\section{Internal Pressure}

Internal Pressure is the measure of the resultant force of attraction and force of repulsion between interacting components of liquid mixture ${ }^{20}$. It is derived from the relation. mixtures were determined by using Ostwald's viscometer.

$$
\pi_{i}=b R T\left(\frac{K \eta}{U}\right)^{\frac{1}{2}}\left(\frac{\rho^{\frac{2}{3}}}{M_{e f f^{\frac{7}{6}}}}\right)
$$

where, $\mathrm{R}$ is gas constant, $\mathrm{T}$ is the absolute temperature, temperature of the system and $\mathrm{K}$ is temperature independent constant. $\mathrm{b}$ stands for the cubic pacing factor ${ }^{5}$.

\section{Acoustic Impedance}

When an ultrasonic wave encounters at interface of two media, the reflection of ultrasonic occur due to the impedance 21,22 . It describes how much resistance and ultrasound beam experiences, as it passes through a medium. It is very important physical quantity for estimating the absorption of sound in the material medium. Acoustic impedance can be obtained from the expression

$$
Z=U \rho
$$

where $\mathrm{U}$ is ultrasonic velocity and $\rho$ is density of liquid mixtures.

\section{Relaxation time}

Relaxation time is the property of the liquid mixture which affects the ultrasonic velocity. There is some correlation between relaxation time and absorption coefficient. It can be computed using the ${ }^{23}$,

$$
\tau=\frac{3}{4} \eta \beta
$$

where, $\eta$ is the viscosity of the liquid mixtures.

\section{Molar Volume}

Molar Volume is the volume occupied by one mole of substance .The molar volume of the liquid mixtures has been calculated using the expression

$$
V_{m}=\left(X_{1} M_{1}+X_{2} M_{2}\right) / \rho
$$

where, $\mathrm{X}_{1}$ and $\mathrm{X}_{1}$ are mole fraction of the solute and solvent and $\mathrm{M}_{1}$ and $\mathrm{M}_{2}$ are molecular weight of the solute and solvent respectively

\section{Classical absorption co efficient}

The classical absorption is always several times less than the actual measured absorption, since it is only due to the viscosity of the medium. The classical absorption coefficient $\left(\alpha / f^{2}\right)$ class can be obtained by

$$
\left(\alpha / f^{2}\right) \text { class }=8 \pi^{2} \eta s / 3 \rho u
$$

\section{Surface Tension}

The surface tension is calculated from ultrasonic velocity and density ${ }^{24}$ as

$$
\sigma=6.3 \times 10^{-4} \rho U^{\frac{3}{2}}
$$

The modified relation of surface tension ${ }^{17}$ is expressed as,

$$
\sigma=10^{-4} T^{\frac{1}{3}} \rho U^{\frac{3}{2}}
$$

\section{Excess Parameters}

The excess functions ${ }^{5}$ for the acoustical parameters are calculated using the relation, 


$$
\mathrm{Y}^{\mathrm{E}}=\mathrm{Y}_{\text {mix }}\left[\mathrm{X}_{1} \mathrm{Y}_{1}+\mathrm{X}_{2} \mathrm{Y}_{2}\right]
$$

The excess viscosity, excess compressibility, excess intermolecular free length, excess acoustic impedance and excess molar volume are derived from the following expressions,

$$
\begin{aligned}
& \eta^{\mathrm{E}}=\eta_{\text {mix }}-\left[\mathrm{X}_{1} \eta_{1}+\mathrm{X}_{2} \eta_{2}\right] \\
& \beta^{\mathrm{E}}=\beta_{\text {mix }}-\left[\mathrm{X}_{1} \beta_{1}+\mathrm{X}_{2} \beta_{2}\right] \\
& \mathrm{L}_{\mathrm{f}}^{\mathrm{E}}=\mathrm{L}_{\mathrm{fmix}}-\left[\mathrm{X}_{1} \mathrm{~L}_{\mathrm{f} 1}+\mathrm{X}_{2} \mathrm{~L}_{\mathrm{f} 2}\right] \\
& \mathrm{Z}^{\mathrm{E}}=\mathrm{Z}_{\text {mix }}-\left[\mathrm{X}_{1} \mathrm{Z}_{1}+\mathrm{X}_{2} \mathrm{Z}_{2}\right] \\
& \mathrm{V}_{\mathrm{m}}^{\mathrm{E}}=\mathrm{V}_{\mathrm{m} \text { mix }}-\left[\mathrm{X}_{1} \mathrm{~V}_{\mathrm{m} 1}+\mathrm{X}_{2} \mathrm{~V}_{\mathrm{m} 2}\right]
\end{aligned}
$$

where, $\eta_{1}$ and $\eta_{2} \beta_{1}$ and $\beta_{2}, \mathrm{~V}_{\mathrm{m} 1}$ and $\mathrm{V}_{\mathrm{m} 2}, \mathrm{~L}_{\mathrm{f} 1}$ and $\mathrm{L}_{\mathrm{f} 2}, \mathrm{Z}_{1}$ and $\mathrm{Z}_{2}$ are the viscosity,adiabatic compressibility, free length acoustic impedance and molar volume of the solute and solvent respectively.

\section{RESULTS AND DISCUSSION}

While mixing two liquids, the molecular interaction between the liquids is due to the presence of dispersive force, charge transfer, hydrogen bonding and dipole induced dipole interactions. The acoustical parameters which are calculated from measured ultrasonic velocity density, and viscosity provide complete information about interaction between ions, dipoles, the intermolecular hydrogen bonding and cohesive and dispersive forces. From the measured and calculated acoustical parameters for the excess parameters like excess viscosity, excess compressibility, excess molar volume, excess acoustic impedance and excess intermolecular free length are calculated The deviation in the experimental and theoretical ultrasonic velocity shows that molecular interactions takes place between unlike molecules. The deviation of experimental values from values calculated using Ideal mixing relation, may be because of compressibility of component liquids is present in the mixtures.

Surface tension, modified surface tension and molar

\begin{tabular}{|c|c|c|c|c|c|}
\hline Mole Fraction & $\begin{array}{l}\mathbf{U} \\
\mathbf{m} / \mathbf{s}\end{array}$ & $\begin{array}{l}\rho \\
\mathbf{K g m}^{-3}\end{array}$ & $\prod_{2}^{\eta \times 10^{3} \mathrm{Nsm}^{-} \sigma_{\text {AUR }}}$ & $\begin{array}{l}\sigma_{\text {MOD }} \\
\mathbf{N m}^{-1}\end{array}$ & 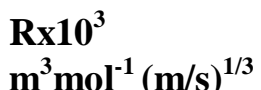 \\
\hline
\end{tabular}
sound velocity along with the measured ultrasonic speed, density, and viscosity for all the five systems at $303.15 \mathrm{~K}$

\begin{tabular}{|c|c|c|c|c|c|c|}
\hline 0.0000 & 1.0000 & 1572 & 1142 & 1.793 & 44875 & 478422.542 \\
\hline 0.1084 & 0.8916 & 1574 & 1141 & 1.720 & 44909 & 478782.542 \\
\hline 0.2148 & 0.7852 & 1578 & 1140 & 1.697 & 45044 & 480232.503 \\
\hline 0.3192 & 0.6808 & 1579 & 1138 & 1.688 & 44998 & 479732.485 \\
\hline 0.4218 & 0.5782 & 1583 & 1135 & 1.663 & 45071 & 480512.470 \\
\hline 0.5225 & 0.4775 & 1593 & 1129 & 1.672 & 45195 & 481832.467 \\
\hline 0.6214 & 0.3786 & 1603 & 1133 & 1.565 & 45830 & 488602.441 \\
\hline 0.7185 & 0.2815 & 1606 & 1129 & 1.510 & 45787 & 488152.429 \\
\hline 0.8140 & 0.1860 & 1611 & 1123 & 1.415 & 45735 & 487592.425 \\
\hline 0.9078 & 0.0922 & 1616 & 1119 & 1.384 & 45808 & 488372.413 \\
\hline 1.0000 & 0.0000 & 1629 & 1118 & 1.369 & 46306 & 493682.401 \\
\hline
\end{tabular}
are presented in Table- 1 .

Table 1 Ultrasonic Speed, Density, Viscosity, Surface tension, Modified surface tension, and Molar sound velocity, for

\begin{tabular}{|c|c|c|c|c|c|c|}
\hline 0.0000 & 1 & 1695 & 1199 & 2.466 & 52710 & 561953.901 \\
\hline 0.1603 & 0.8397 & 1681 & 1187 & 2.288 & 51544 & 549523.665 \\
\hline 0.3005 & 0.6995 & 1677 & 1181 & 2.229 & 51110 & 544893.449 \\
\hline 0.4241 & 0.5759 & 1666 & 1173 & 2.138 & 50282 & 536073.260 \\
\hline 0.5339 & 0.4661 & 1651 & 1165 & 1.976 & 49242 & 524983.091 \\
\hline 0.6321 & 0.3679 & 1653 & 1159 & 1.838 & 49045 & 522882.944 \\
\hline 0.7205 & 0.2795 & 1639 & 1148 & 1.711 & 47976 & 511492.814 \\
\hline 0.8132 & 0.1868 & 1641 & 1141 & 1.687 & 47779 & 509392.676 \\
\hline 0.8730 & 0.1270 & 1640 & 1132 & 1.560 & 47361 & 504932.583 \\
\hline 0.9393 & 0.0607 & 1628 & 1124 & 1.438 & 46527 & 496042.493 \\
\hline 1.0000 & 0.0000 & 1644 & 1116 & 1.528 & 46841 & 499382.414 \\
\hline \multicolumn{7}{|c|}{ System III:Ammonium Persulphate+Zinc sulphate } \\
\hline 0.0000 & 1 & 1610 & 1176 & 1.738 & 47876 & 510422.866 \\
\hline 0.1228 & 0.8772 & 1617 & 1168 & 1.449 & 47872 & 510382.815 \\
\hline
\end{tabular}
the systems I,II ,III,IV and V at 303.15K.

$\mathrm{X}_{2}$
System I:Ammonium Persulphate+Copper sulphate

System II:Ammonium Persulphate +Ferrous Ammonium Sulphate 
ULTRASONIC TECHNIQUE

\begin{tabular}{|c|c|c|c|c|c|c|c|}
\hline 0.2395 & 0.7605 & 1632 & 1165 & \multicolumn{2}{|c|}{1.423} & 48373 & 515712.762 \\
\hline 0.3507 & 0.6493 & 1634 & 1158 & \multicolumn{2}{|c|}{1.377} & 48168 & 513532.714 \\
\hline 0.4565 & 0.5435 & 1634 & 1153 & \multicolumn{2}{|c|}{1.276} & 47964 & 511362.657 \\
\hline 0.5575 & 0.4425 & 1631 & 1146 & \multicolumn{2}{|c|}{1.270} & 47576 & 507222.613 \\
\hline 0.6540 & 0.3460 & 1650 & 1142 & \multicolumn{2}{|c|}{1.185} & 48210 & 513982.573 \\
\hline 0.7462 & 0.2538 & 1643 & 1140 & \multicolumn{2}{|c|}{1.177} & 47802 & 509622.519 \\
\hline 0.8344 & 0.1656 & 1662 & 1133 & \multicolumn{2}{|c|}{1.165} & 48354 & 515512.488 \\
\hline 0.9190 & 0.0810 & 1663 & 1125 & \multicolumn{2}{|c|}{1.073} & 48059 & 512362.455 \\
\hline 1.0000 & 0.0000 & 1633 & 1119 & \multicolumn{2}{|c|}{1.101} & 46546 & 496242.401 \\
\hline \multicolumn{8}{|c|}{ System IV:Ammonium Persulphate+Magnesium Sulphate } \\
\hline 0.0000 & 1.0000 & & 1636 & 1114 & 1.747 & 46426 & 494952.608 \\
\hline 0.1071 & 0.8929 & & 1631 & \multicolumn{2}{|r|}{1.626} & 46042 & 490862.595 \\
\hline 0.2126 & 0.7874 & & 1618 & \multicolumn{2}{|l|}{1110} & 45505 & 485142.566 \\
\hline 0.3164 & 0.6836 & & 1616 & \multicolumn{2}{|l|}{1111} & 45457 & 484622.544 \\
\hline 0.4186 & 0.5814 & & 1622 & \multicolumn{2}{|l|}{1113} & 45793 & 488212.522 \\
\hline 0.5192 & 0.4808 & & 1637 & \multicolumn{2}{|l|}{1113} & 46433 & 495032.510 \\
\hline 0.6183 & 0.3817 & & 1656 & \multicolumn{2}{|l|}{1112} & 47216 & 503382.503 \\
\hline 0.7159 & 0.2841 & & 1663 & \multicolumn{2}{|l|}{1115} & 47628 & 507772.479 \\
\hline 0.8120 & 0.1880 & & 1630 & \multicolumn{2}{|r|}{1.219} & 46100 & 491482.452 \\
\hline 0.9067 & 0.0933 & & 1648 & \multicolumn{2}{|l|}{1112} & 46864 & 499632.442 \\
\hline 1.0000 & 0.0000 & & 1661 & 1111 & 1.055 & 47401 & 505352.432 \\
\hline \multicolumn{8}{|c|}{ System V:Ammonium Persulphate +Ammonium sulphate } \\
\hline 0.0000 & 1.0000 & & 16241070 & \multicolumn{2}{|c|}{1.213} & 44103 & 470191.450 \\
\hline 0.0604 & 0.9396 & & 16181069 & \multicolumn{2}{|c|}{1.145} & 43813 & 467101.525 \\
\hline 0.1265 & 0.8735 & & 16261075 & \multicolumn{2}{|c|}{1.149} & 44385 & 473201.579 \\
\hline 0.1988 & 0.8012 & & 16401082 & \multicolumn{2}{|c|}{1.155} & 45257 & 482491.648 \\
\hline 0.2785 & 0.7215 & & 16481086 & \multicolumn{2}{|c|}{1.112} & 45763 & 487891.729 \\
\hline 0.3677 & 0.6333 & & 16641090 & \multicolumn{2}{|c|}{1.096} & 46591 & 496721.823 \\
\hline 0.4648 & 0.5352 & & 16431089 & \multicolumn{2}{|c|}{1.115} & 45689 & 487101.916 \\
\hline 0.5747 & 0.4253 & 1652 & 1104 & \multicolumn{2}{|c|}{1.124} & 46709 & 497982.007 \\
\hline 0.6985 & 0.3015 & 1637 & 1109 & & & 46284 & 493442.118 \\
\hline 0.8390 & 0.1610 & 1658 & 1194 & & & 50749 & 541052.109 \\
\hline 1.0000 & 0.0000 & 1633 & 1118 & & & 46505 & 495802.403 \\
\hline
\end{tabular}

From the variation in values of surface tension for the five systems listed as in the Table 1. It is inferred that the presence of attractive interactions between the liquid mixtures. There is the migration of species having lowest surface tension at the interface of two media. This migration produces the variation in the surface tension of liquid mixtures. Addition of solute increases the surface tension accompanied with variation of mean free length $^{25,26}$.In our present study, the non linearity in the surface tension of the solutions of all the inorganic salt mixtures confirm the migration of constituent molecules and strong interactions in liquid mixtures.

The adiabatic compressibility, intermolecular free length and acoustic impedance are listed in the Table 2.The decreasing trend in the Molar volume for the systems I-V is noted from the Table 2.The linear variation in the molar volume with the concentration show the adhesive forces between the constituent molecules of the liquid mixtures.

The variation in the adiabatic compressibility shows the variation depending upon the concentration of solute. It is due to the change in ultrasonic velocity. The similar results are obtained by Elangovan and Mullainathan ${ }^{4}$.The increasing trend in the compressibility of mixtures with

increase in concentration of solute molecule may be attributed to the presence of dipolar interactions between unlike molecules. The decrease in intermolecular systems indicates the variation in the structural arrangement in the molecules. The non-linear variation of intermolecular free length observed in all the five sulphate mixtures of with concentration of the solute may arise from the hydrogen bonding.

The non linearity in the internal pressure is used to measure the attractions repulsions of the molecules in the liquid systems. Decrease in the values of internal pressure with increasing mole fraction observed in system I, IV and $\mathrm{V}$, and the increase in the internal pressure values in the systems II and III exhibit the increase in the attractive forces between the components ${ }^{27}$.

The increasing trend in the acoustic impedance for the system I is observed from the Table 2. Acoustic impedance values are decreased with increase in mole fractions in the Systems II, III, IV and V. These variations suggest that the presence of complex formation in the 
solutions and it is attributed due to solute solvent interaction. The relaxation time with the order of $10^{-13}$ seconds, may be because of structural relaxation process $^{28}$. The decreasing values of relaxation time with the increase in concentration is observed in all the five systems confirms solute solvent interactions. The decreasing trend in the Molar volume for the systems I-V is noted from the Table 2.The linear variation in the molar volume with the concentration show the adhesive forces between the constituent molecules of the liquid mixtures.

Table 2 provides the values of classical absorption coefficient for all the five systems at $303.15 \mathrm{k}$. The uniformity in the decreasing trend in the values of classical absorption co efficient with concentration is the clear evidence solute solvent interactions between the constituent molecules.

Table 2 Adiabatic compressibility, Inter molecular free length, Acoustic impedance, Relaxation time, Classical absorption coefficient, Internal pressure and molar volume for the systems I, II, III, IV and V at 303.15 K

Mole Fraction

$$
\begin{array}{lllll}
\beta \times 10^{10} & \mathrm{~L}_{\mathrm{f}} \mathbf{X 1 0}^{11} & \mathrm{Zx10}^{-6} & \tau \times 10^{13} & \alpha / \mathrm{f}^{2} \times 10^{15} \\
\mathrm{Kg}^{-} \mathbf{m s}^{2} & \mathrm{~m} & \mathrm{Kgm}^{-1} & \text { sec } & \text { Neperm }^{-1}
\end{array}
$$

\section{$\pi_{\mathrm{i}} \times 10^{6} \quad \mathrm{~V}_{\mathrm{m}} \times 10^{6} \mathrm{~m}^{3}$} atm

$\mathrm{x}_{1}$

$\mathrm{X}_{2}$

System I:Ammonium Persulphate+Copper sulphate

$\begin{array}{lllllllll}0.0000 & 1.0000 & 3.540 & 3.763 & 1.796 & 8.463 & 10.613 & 6.336 & 218.57 \\ 0.1084 & 0.8916 & 3.536 & 3.761 & 1.797 & 8.109 & 10.156 & 6.134 & 218.78 \\ 0.2148 & 0.7852 & 3.520 & 3.753 & 1.800 & 7.964 & 9.950 & 6.081 & 214.94 \\ 0.3192 & 0.6808 & 3.523 & 3.754 & 1.797 & 7.931 & 9.903 & 6.123 & 213.37 \\ 0.4218 & 0.5782 & 3.513 & 3.748 & 1.798 & 7.787 & 9.697 & 6.067 & 211.93 \\ 0.5225 & 0.4775 & 3.493 & 3.738 & 1.798 & 7.788 & 9.642 & 6.108 & 211.27 \\ 0.6214 & 0.3786 & 3.433 & 3.706 & 1.817 & 7.162 & 8.808 & 5.751 & 208.56 \\ 0.7185 & 0.2815 & 3.434 & 3.706 & 1.814 & 6.914 & 8.490 & 5.588 & 207.42 \\ 0.8140 & 0.1860 & 3.432 & 3.705 & 1.809 & 6.476 & 7.927 & 5.253 & 206.83 \\ 0.9078 & 0.0922 & 3.421 & 3.699 & 1.809 & 6.315 & 7.707 & 5.165 & 205.61 \\ 1.0000 & 0.0000 & 3.371 & 3.672 & 1.821 & 6.152 & 7.449 & 5.115 & 204.05\end{array}$

System II:Ammonium Persulphate +Ferrous Ammonium Sulphate

$\begin{array}{lllllllll}0.0000 & 1.0000 & 2.903 & 3.408 & 2.032 & 9.543 & 11.100 & 4.929 & 327.17 \\ 0.1603 & 0.8397 & 2.981 & 3.453 & 1.995 & 9.096 & 10.670 & 4.970 & 308.20 \\ 0.3005 & 0.6995 & 3.009 & 3.469 & 1.981 & 8.946 & 10.517 & 5.022 & 290.32 \\ 0.4241 & 0.5759 & 3.069 & 3.504 & 1.955 & 8.751 & 10.357 & 5.385 & 274.94 \\ 0.5339 & 0.4661 & 3.148 & 3.549 & 1.923 & 8.294 & 9.905 & 5.342 & 261.52 \\ 0.6321 & 0.3679 & 3.160 & 3.555 & 1.915 & 7.745 & 9.241 & 5.272 & 248.99 \\ 0.7205 & 0.2795 & 3.083 & 3.511 & 1.881 & 7.401 & 8.907 & 5.225 & 238.65 \\ 0.8132 & 0.1868 & 3.072 & 3.506 & 1.872 & 7.321 & 8.797 & 5.474 & 226.39 \\ 0.8730 & 0.1270 & 3.045 & 3.490 & 1.856 & 6.833 & 8.218 & 5.273 & 219.93 \\ 0.9393 & 0.0607 & 2.980 & 3.453 & 1.830 & 6.435 & 7.793 & 5.132 & 211.88 \\ 1.0000 & 0.0000 & 3.014 & 3.472 & 1.834 & 6.758 & 8.108 & 5.648 & 204.54 \\ \text { System III:Ammonium Persulphate+Zinc sulphate } & & & & 5.187 & 244.52 \\ 0.0000 & 1.00001 & 3.279 & 3.622 & 1.894 & 7.600 & 9.306 & 4.417 & 239.85 \\ 0.1228 & 0.8772 & 3.273 & 3.618 & 1.890 & 6.322 & 7.708 & 4.418 & 234.61 \\ 0.2395 & 0.7605 & 3.224 & 3.591 & 1.901 & 6.116 & 7.391 & 4.374 & 230.43 \\ 0.3507 & 0.6493 & 3.236 & 3.598 & 1.891 & 5.939 & 7.168 & 4.157 & 225.60 \\ 0.4565 & 0.5435 & 3.249 & 3.605 & 1.883 & 5.529 & 6.673 & 4.243 & 221.99 \\ 0.5575 & 0.4425 & 3.279 & 3.621 & 1.870 & 5.554 & 6.714 & 4.93 \\ 0.6540 & 0.3460 & 3.218 & 3.588 & 1.884 & 5.084 & 6.077 & 4.462 & 217.77 \\ 0.7462 & 0.2538 & 3.252 & 3.607 & 1.872 & 5.102 & 6.124 & 4.097 & 213.47 \\ 0.8344 & 0.1656 & 3.196 & 3.575 & 1.883 & 4.965 & 5.891 & 4.096 & 210.01 \\ 0.9190 & 0.0810 & 3.214 & 3.586 & 1.871 & 4.597 & 5.463 & 3.845 & 207.19 \\ 1.0000 & 0.0000 & 3.350 & 3.661 & 1.828 & 4.491 & 5.934 & 4.104 & 203.86\end{array}$




\section{RESEARCH ON ION-SOLVENT INTERACTIONS IN THE INORGANIC LIQUID MIXTURES BY ULTRASONIC TECHNIQUE}

\section{System IV:Ammoniumpersulphate+Magnesium Sulphate}

$\begin{array}{lllllll}0.0000 & 1.0000 & 3.545 & 3.766 & 1.737 & 5.732 & 6.969 \\ 0.1071 & 0.8929 & 3.575 & 3.781 & 1.729 & 5.455 & 6.655 \\ 0.2126 & 0.7874 & 3.520 & 3.752 & 1.747 & 5.393 & 6.547 \\ 0.3164 & 0.6836 & 3.438 & 3.708 & 1.774 & 5.295 & 6.375 \\ 0.4186 & 0.5814 & 3.391 & 3.683 & 1.789 & 5.028 & 6.022 \\ 0.5192 & 0.4808 & 3.315 & 3.641 & 1.813 & 4.842 & 5.744 \\ 0.6183 & 0.3817 & 3.402 & 3.689 & 1.789 & 5.055 & 6.073 \\ 0.7159 & 0.2841 & 3.318 & 3.643 & 1.824 & 4.972 & 5.939 \\ 0.8120 & 0.1880 & 3.364 & 3.668 & 1.816 & 4.917 & 5.929 \\ 0.9067 & 0.0933 & 3.049 & 3.492 & 1.979 & 4.699 & 5.596 \\ 1.0000 & 0.0000 & 3.352 & 3.662 & 1.827 & 4.840 & 5.850\end{array}$

System V:Ammonium persulphate +ammonium sulphate

$\begin{array}{lllllllll}0.0000 & 1.0000 & 3.355 & 3.663 & 1.822 & 7.813 & 9.416 & 5.921 & 221.35 \\ 0.0604 & 0.9396 & 3.388 & 3.681 & 1.810 & 7.343 & 8.877 & 5.565 & 220.42 \\ 0.1265 & 0.8735 & 3.442 & 3.711 & 1.796 & 7.098 & 8.651 & 5.390 & 218.57 \\ 0.1988 & 0.8012 & 3.447 & 3.713 & 1.795 & 6.888 & 8.405 & 5.278 & 216.74 \\ 0.2785 & 0.7215 & 3.416 & 3.697 & 1.805 & 6.677 & 8.118 & 5.199 & 214.63 \\ 0.3677 & 0.6333 & 3.354 & 3.663 & 1.822 & 6.216 & 7.488 & 4.930 & 212.96 \\ 0.4648 & 0.5352 & 3.278 & 3.621 & 1.841 & 5.873 & 6.991 & 4.747 & 211.55 \\ 0.5747 & 0.4253 & 3.244 & 3.602 & 1.854 & 5.222 & 6.193 & 4.297 & 209.27 \\ 0.6985 & 0.3015 & 3.385 & 3.680 & 1.812 & 5.502 & 6.656 & 4.456 & 208.31 \\ 0.8390 & 0.1610 & 3.312 & 3.640 & 1.832 & 5.582 & 6.679 & 4.611 & 206.77 \\ 1.0000 & 0.0000 & 3.261 & 3.612 & 1.846 & 4.585 & 5.443 & 3.847 & 205.36\end{array}$

Excess Viscosity, Excess Compressibility, Excess Free length, Excess impedance and Excess molar volume for the systems at $303.15 \mathrm{~K}$ are presented in the Table 3.The excess values are the appropriate tool for investigating the degree of molecular interactions in the liquid mixtures. The excess functions exhibit the deviations in ultrasonic velocity and viscosity which are due to the strong or weak interactions between the unlike molecules of the mixtures ${ }^{14}$. The positive values of $\mathrm{V}_{\mathrm{f}}^{\mathrm{E}}$ and $\mathrm{L}_{\mathrm{f}}{ }^{\mathrm{E}}$ shows the occurrence of dissociation of hydrogen bonding between like molecules than the formation of new bonds between unlike molecules.. The negative values of $\mathrm{V}_{\mathrm{f}}^{\mathrm{E}}$ and $\mathrm{L}_{\mathrm{f}}{ }^{\mathrm{E}}$ are may be the result of complex formation. The positive and negative values of excess functions are the influence of dissociation or association between unlike molecules. The dipole induced dipole and dipole-dipole interactions and the dispersive forces make the excess values to be negative and positive values respectively $\mathrm{y}^{29-30}$. The excess viscosity values are negative for all concentrations for the systems II-V. The positive values of excess viscosity at mid concentrations observed in the system I reflect the increase in the strength of interaction in the solutions [14].

Table 3 Excess Viscosity, Excess Compressibility, Excess Free length, Excess impedance and Excess molar volume for the systems I, II, III, IV and V at 303.15K.

\begin{tabular}{|c|c|c|c|c|c|c|}
\hline \multicolumn{2}{|l|}{ Mole Fraction } & $\begin{array}{l}\eta^{\mathrm{Ex}} 10^{3} \\
\mathrm{Nsm}^{-2}\end{array}$ & $\begin{array}{l}\beta^{\mathrm{E}} \mathbf{x 1 0}^{10} \\
\mathrm{Kg}^{-1} \mathrm{~ms}^{2}\end{array}$ & $\begin{array}{l}\mathbf{L}_{\mathbf{f}}^{\mathrm{E}} \times \mathbf{x 1 0}^{11} \\
\mathrm{M}\end{array}$ & $\begin{array}{l}Z^{\mathrm{Ex}} \mathbf{1 0}^{-6} \\
\mathrm{Kgm}^{-2} \mathrm{~s}^{-1}\end{array}$ & $\begin{array}{l}V_{m}^{E} x 1 \\
m^{3}\end{array}$ \\
\hline $\mathrm{x}_{2}$ & $\mathrm{x}_{2}$ & & & & & \\
\hline \multicolumn{7}{|c|}{ System I:Ammonium Per sulphate+ Copper sulphate } \\
\hline 0.1084 & 0.8916 & -0.027 & 0.013 & 0.007 & -0.003 & 1.784 \\
\hline 0.2148 & 0.7852 & -0.005 & 0.016 & 0.009 & -0.002 & -0.511 \\
\hline 0.3192 & 0.6808 & 0.031 & 0.037 & 0.020 & -0.007 & -0.565 \\
\hline 0.4218 & 0.5782 & 0.049 & 0.044 & 0.024 & -0.009 & -0.516 \\
\hline 0.5225 & 0.4775 & 0.101 & 0.041 & 0.022 & -0.012 & 0.287 \\
\hline 0.6214 & 0.3786 & 0.035 & -0.002 & -0.001 & 0.005 & -0.987 \\
\hline 0.7185 & 0.2815 & 0.022 & 0.015 & -0.008 & -0.001 & -0.717 \\
\hline 0.8140 & 0.1860 & -0.032 & 0.029 & 0.016 & -0.008 & 0.079 \\
\hline 0.9078 & 0.0922 & -0.024 & 0.035 & 0.019 & -0.010 & 0.221 \\
\hline
\end{tabular}


System II:Ammonium Persulphate +Ferrous Ammonium sulphatemmonium Sulphate

$\begin{array}{llll}0.1603 & 0.8397 & -0.027 & 0.060 \\ 0.3005 & 0.6995 & 0.045 & 0.073 \\ 0.4241 & 0.5759 & 0.070 & 0.119 \\ 0.5339 & 0.4661 & 0.011 & 0.186 \\ 0.6321 & 0.3679 & -0.035 & 0.186 \\ 0.7205 & 0.2795 & -0.079 & 0.099 \\ 0.8132 & 0.1868 & -0.016 & 0.079 \\ 0.8730 & 0.1270 & -0.087 & 0.045 \\ 0.9393 & 0.0607 & -0.147 & -0.027\end{array}$

System III:Ammonium Persulphate+Zinc sulphate

$\begin{array}{lllllll}0.1228 & 0.8772 & -0.211 & -0.015 & -0.009 & 0.004 & -0.086 \\ 0.2395 & 0.7605 & -0.163 & -0.072 & -0.040 & 0.023 & -0.970 \\ 0.3507 & 0.6493 & -0.138 & -0.068 & -0.038 & 0.021 & -0.998 \\ 0.4565 & 0.5435 & -0.171 & -0.062 & -0.034 & 0.019 & -1.879 \\ 0.5575 & 0.4425 & -0.112 & -0.040 & -0.220 & 0.013 & -1.719 \\ 0.6540 & 0.3460 & -0.136 & -0.108 & -0.060 & -0.007 & -2.336 \\ 0.7462 & 0.2538 & -0.086 & -0.080 & -0.044 & 0.027 & -3.194 \\ 0.8344 & 0.1656 & -0.041 & -0.142 & -0.079 & 0.044 & -3.362 \\ 0.9190 & 0.0810 & -0.080 & -0.130 & -0.072 & 0.037 & -3.024\end{array}$

System IV:Ammonium per sulphate+Magnesium sulphate

$\begin{array}{lllllll}0.1071 & 0.8929 & -0.047 & 0.043 & 0.024 & -0.015 & 0.781 \\ 0.2126 & 0.7874 & -0.053 & 0.107 & 0.058 & -0.031 & 0.623 \\ 0.3164 & 0.6836 & -0.029 & 0.122 & 0.067 & -0.035 & 0.451 \\ 0.4186 & 0.5814 & 0.009 & 0.100 & 0.055 & -0.027 & -0.026 \\ 0.5192 & 0.4808 & 0.003 & 0.049 & 0.027 & -0.012 & -0.087 \\ 0.6183 & 0.3817 & 0.025 & -0.018 & -0.010 & 0.005 & 0.086 \\ 0.7159 & 0.2841 & -0.044 & -0.044 & -0.024 & 0.015 & -0.632 \\ 0.8120 & 0.1880 & 0.034 & 0.106 & 0.058 & -0.029 & -0.053 \\ 0.9067 & 0.0933 & 0.145 & 0.042 & 0.023 & -0.011 & -0.087\end{array}$

System V:Ammonium Persulphate + Ammonium Sulphate

$\begin{array}{lllllll}0.0604 & 0.9396 & -0.060 & 0.041 & 0.022 & -0.014 & 1.677 \\ 0.1265 & 0.8735 & -0.047 & -0.007 & 0.003 & -0.002 & 0.714 \\ 0.1988 & 0.8012 & -0.032 & -0.007 & -0.037 & 0.019 & 0.381 \\ 0.2785 & 0.7215 & -0.065 & -0.100 & -0.054 & 0.027 & 0.511 \\ 0.3677 & 0.6333 & -0.071 & -0.163 & -0.090 & 0.041 & 0.671 \\ 0.4648 & 0.5352 & -0.038 & -0.054 & -0.029 & 0.010 & 1.520 \\ 0.5747 & 0.4253 & -0.014 & -0.116 & -0.063 & 0.035 & 0.003 \\ 0.6985 & 0.3015 & -0.026 & -0.046 & -0.249 & 0.016 & -0.055 \\ 0.8390 & 0.1610 & 0.052 & -0.334 & -0.186 & 0.166 & -12.831\end{array}$

The negative excess compressibility indicates the strong hetero molecular interactions of the constituent molecules. The negative values are due to the charge transfer, dipole-dipole and dipole - induced dipole interaction and by the hydrogen bonding between unlike components. Positive excess compressibility shows the weak interactions which will arise from the dispersive Forces $^{14,31}$. In our present work, the positive values of adiabatic compressibility in the system I, II and IV exhibit the weak interaction may be due to molecular dissociation. The compressibility is negative in the systems III and V. It is the evidence for the presence of strong molecular association.

$\begin{array}{lll}0.035 & -0.005 & 0.688 \\ 0.042 & 0.009 & 0.000 \\ 0.069 & 0.007 & -0.223 \\ 0.107 & -0.003 & -0.178 \\ 0.107 & 0.008 & -0.666 \\ 0.057 & -0.008 & -0.165 \\ 0.045 & 0.001 & -0.587 \\ 0.026 & -0.003 & -0.184 \\ -0.016 & -0.016 & -0.104\end{array}$

$-0.086$

$-0.998$

1.879

$-2.336$

$-3.194$

$-3.024$

0.781

0.623

0.451

$-0.026$

$-0.087$

$-0.632$

$-0.087$

It is observed that excess free length values are negative for the systems III and V. The negative values of excess intermolecular free length is mainly due to the hydrogen bonding between the unlike molecules ${ }^{32}$. The positive values of $\mathrm{L}_{\mathrm{f}}$ indicate the weak molecular interaction between the components of mixtures, which may arise from dispersion forces ${ }^{33}$. The excess acoustic impedance values show the negative values for all the systems except systems III and V. The negative acoustic impedance values may arise from the molecular interaction between the unlike molecules. Acoustic impedance is positive for the higher concentrations of the 


\section{RESEARCH ON ION-SOLVENT INTERACTIONS IN THE INORGANIC LIQUID MIXTURES BY ULTRASONIC TECHNIQUE}

systems III and V. It may be attributed due to weak interactions. The excess molar volume values are negative in all the five systems for entire composition. This is due to the reason that the constituent molecules are brought in to closer and is the evidence of strong interactions. Free dipoles of ammonium per sulphate induce the moments in the dipoles of other sulphate anions of the liquid mixtures.

\section{CONCLUSION}

The measured values of ultrasonic velocity, density, viscosity, and computed acoustical parameters at $303.15 \mathrm{k}$ for ammonium per sulphate with five different sulphate anions provide the knowledge about the existence of hydrogen bonding between unlike molecules. Evaluated excess viscosity, excess compressibility and excess free volume confirmed the presence of hydrogen bonding, and dipolar interactions.

\section{REFERENCES}

1. K.Rajagopal and S.Chenthilnath, 'Excess thermodynamic studies of binary liquid mixtures of 2-methyl-2-propanol with ketones' Ind. J. Pure and App. Phy. , 48, 326 (2010).

2. S.Parveen, Divya Shukla, ShashiSingh, K.P.Singh, Manisha Gupta and J.P.Shukla, 'Ultrasonic velocity, density, viscosity and their excess parameters of the binary mixtures of tetrahydrofuran with methanol and o-cresol at varying temperatures'App. Acous., 70(3),507 (2009).

3. Riyazuddeen and Sadaf Afrin, 'Ultrasonic Velocities and Densities of L-Phenylalanine, L-Leucine, L-Glutamic Acid, and L-Proline $+2 \mathrm{~mol} \cdot \mathrm{L}-1$ Aqueous $\mathrm{NaCl}$ and 2 mol.L-1 Aqueous NaNO3 Solutions from (298.15 to 328.15) K' , J. Chem. Eng. Data, 55, 2643-2648(2010).

4. Elangovan and S.Mullainathan, 'Intermolecular Interaction Studies in Binary Mixture of Methyl formate with Methanol at Various Temperatures', Asian J.Chem.,26(1)137 (2014).

5. Baldevraj, P.Palanichamy and V.Rajendran Science and Technology of Ultrasonics, Narosa publishing House, 2006.

6. F.Amireche-Ziar, D.Richon and F.B. Belaribi , 'Excess molar enthalpies for binary mixtures of 1,2-dichloroethane with ethers at $298.15 \mathrm{~K}$ and atmospheric pressure Fluid Phase Equ., 337 ,255 (2013) .

7. Ernesto Vercher, A. Vicent Orchilles, Francisco J. Llopis, Vicenta Gonzalez-Alfaro, and Antoni Martínez-Andreu , ‘ Ultrasonic and Volumetric Properties of 1-Ethyl-3methylimidazolium Trifluoromethanesulfonate Ionic Liquid with 2-Propanol or Tetrahydrofuran at Several Temperatures', J. Chem. Eng. Data, 56, 4633-4642,( 2011).

8. K.Gokhan Savaroglu and Ertunc Aral, 'Excess isentropic compressibility and speed of sound of the ternary mixture 2-propanol + diethyl ether $+\mathrm{n}$-hexane and the constituent binary mixtures at $298.15 \mathrm{~K}^{\prime}$, PRAMANA, 66( 2),435 (2006) .

9. V.Sastry and M.K. Valand, 'Thermodynamics of Acrylic Ester-Organic Solvent Mixtures. V. Viscosities and Excess Viscosities of Alkyl Acrylates-l-Alcohol Binary Mixtures at 298.15 and $308.15 \mathrm{~K}$, Int. J. Thermophys., 18(6),1387 (1997).

10. H.Eyring and M.S.John, 'Significant Liquid Structure', Wiley, New York, (1969).

11. M.Umadevi, R.Kesavasamy , K.Rathina and R. Mahalakshmi', 'Studies on liquid-liquid interactions of some ternary mixtures by density, viscosity and ultrasonic speed measurements', J. Mol. Liq., 219,820 (2016).
12. F.Comeli ,S.Ottani,R. Francesconi and C.Castellari, Densities, Viscosities and refractive Indices of Binary Mixtures containing n-Hexane + Components of Pine Resins and Essential oils at 298.15 K', J .Chem. Eng. Data , 47(1),93(2002).

13. A.Henni, A.Naami and P.Tontiwachwuthikul, 'Densities, viscosities and derived functions of binary mixtures: (Triethylene glycol dimethyl ether + water $)$ and $(\mathrm{N}-$ acetylmorpholine + water) from $298.15 \mathrm{~K}$ to $343.15 \mathrm{~K}^{\prime} \mathrm{J}$ Chem. Eng .Data., 50,1038 (2005).

14. R.J.Fort and W.R.Moore, 'Adiabatic compressibilities of binary liquid mixtures', Trans. Faraday Soc., 61, 2102(1965).

15. D.Rahul ,T.Srinivasa Krishna M. Gowrisankar and D.Ramachandran, 'Molecular interactions and theoretical estimation of ultrasonic speeds using scaled particle theory in binary mixtures of 3 chloroaniline and 1- alkanols (C6C10) at different temperatures' J, Mol, Liq, 212,618 (2015).

16. S.Ravichandran and K.Ramanathan, 'Molecular interactions and excess thermodynamic properties of mixed solutions of Zinc sulphate and Zinc nitrate at $303 \mathrm{~K}$ by ultrasonic method', Int. J. App. Bio. and Phar. Tech., 1 2,695 (2010) .

17. K.Altenberg, Z.Phy. Chem.,195,145 (1950).

18. J.Blitz , 'Fundamentals of Ultrasonics' Butter Worths, London,.14,53 (1967).

19. Jacobson B, 'Intermolecular Free Lengths in the Liquid State. I. Adiabatic and Isothermal Compressibilities', Acta Chem Scandi ,6(1952) 1485.

20. V.Kannappan,B.S.Shanthi and D.Jonathan, 'Ultrasonic investigation on segmental motion of some polymers in solution',Ind.J.Chem.,53 A,688 (2014).

21. K.R.Nemade and S.A. Waghuley, 'Molecular interactions in $\mathrm{CdCl}_{2} / \mathrm{H}_{2} \mathrm{C}_{2} \mathrm{O}_{4}$ nanofluid using acoustical studies at room temperature', Ind. J. Pure and App. Phy., 53,27 (2015).

22. A.B.Naik, 'Densities, viscosities, speed of sound and some acoustical parameter studies of substituted pyrazoline compounds at different temperatures', Ind. J. Pure and App. Phy. 53,670 (2015).

23. Jean Timmermans, 'Physico Chemical constants of organic components' Elsevier Pub.Co.NewYork (1950).

24. R.Auerbach , 'Oberflachen Sannung and Schallgeschwinding Keit', Experientia, 473 (1984).

25. K.Rathina,,H.B.Ramalingam',R.Mahalakshmi and M.Umadevi, 'Thermo acoustical characterization of several inorganic salts in polyvinyl pyrrolidone at $303.15 \mathrm{~K}$, 308.15K, 313.15K' Zeitschrift für Physikalische Chemie , 231(9) 1507(2017).

26. S.Ravichandran, and K.Ramanathan, 'Acoustical properties and surface tension study of some potassium salts in Polyacrlamide solution at 303K', Res. J Chem Sci., 2,(10) 49(2012).

27. R.Sabesan, M.Natarajan and M.Sargurumoorthy, 'Ultrasonic studies of molecular interactions in hydroxylcarbonyl system' J.Pure and Appl.Ultrason. VIII(1).20,(1980).

28. L.E.Kinsler,A.R.Rray, 'Fundamentals of Acoustics' (Willey Eastern, New Delhi) 1989.

29. Prasad Ghanta, Muralidhar Reddy Kalimi,Padamasuvarna Reniguntla, Madhu Mohan Tadavarthi, and Vijaya Krishna Tadekoru, 'Density and Speed of Sound of the Binary Mixture of 1-Butyl-3-Methylimidazolium Bis(trifluoromethylsulfonyl)imide + 2-Methoxyethanol from $\mathrm{T}=(298.15$ to 323.15$) \mathrm{K}$ at Atmospheric Pressure',J.Chem. Eng. Data, 62,3903(2017).

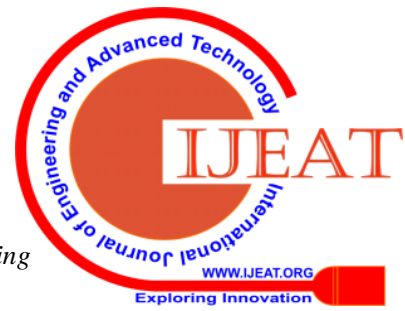


30. M.Umadevi, R.Kesavasamy, V.Ponnusamy, N.S.Priya and K.Ratina , 'Intermolecular interactions in ternary liquid mixtures by ultrasonic measurements', Ind. J. Pure and App. Phy.,53,796 (2015).

31. G.R.Sathyanarayana,D.Balakaruna Kumar, K.Sujatha,G.Lakshmanarao and C.Rambabu, 'Probing the intermolecular interactions in the binary liquid mixtures of o-chlorophenol with alkoxyethanols through ultrasonic ,transport anf FT-IR spectroscopic studies at different temperatures', J. Mol. Liq,216,526 (2016).

32. M.E.Bai,M.C.S.Subha,G.N.Swamy and K.C.Rao, 'Acoustical studies of molecular interactions in binary liquid mixtures of butoxy ethanol with some amines at 308.15 K', J.Pure and App. Ultrason. 2679 (2) (2004).

33. T.Sumathi and J.Umamaheswari, 'Ultrasonic and theoretical studies of some ternary liquid mixtures at various temperatures', Ind. J.Pure.Appl.Phys.47 782 (2009). 